\title{
Dionysos en Córdoba. Sobre unos relieves de temática dionisíaca en Colonia Patricia
}

\author{
Dionysos in Cordova. Some reliefs of dionysiac thematic in Colonia Patricia
}

\author{
Carlos Márquez, carlos.marquez@uco.es, https://orcid.org/0000-0003-3610-3207, Universidad de Córdoba, España
}

\begin{abstract}
Resumen
Abordamos a continuación el estudio de cuatro piezas que hoy se encuentran depositadas en tres distintos lugares (Museo Arqueológico de Córdoba y colecciones privadas) pero que con seguridad formaron parte, en su día, de un único altar del periodo augusteo-tiberiano en la Córdoba romana. Se ha realizado un análisis detallado de sus características, tanto de estilo como de técnica, y se han desechado otras posibles funciones (en concreto la de pedestal) para otorgarle una función de altar; para facilitar al lector la comprensión de sus características se ha realizado un modelo donde se han encajado los cuatro fragmentos. Su riqueza temática, características de labra, estilo y dimensiones, así como los paralelos localizados, avalan una importación desde la capital del imperio en la primera mitad del siglo I de nuestra era, al igual que otras piezas conocidas en la ciudad. Este altar estaría elaborado en diversas piezas que se montarían in situ y que estimamos formarían parte de la decoración de uno de los recintos monumentales de la que fue capital de la Prouincia Baetica, con toda probabilidad el teatro habida cuenta de la vinculación estrecha entre la temática dionisíaca con dicho edificio. La restitución virtual del altar demuestra que se trataría de un tipo muy peculiar para esta clase de elementos sin paralelos exactos conocidos hasta el momento. Con todo ello, la capital de la provincia Baetica reafirma para esta época un comercio directo de piezas de extraordinaria calidad destinadas a embellecer los recintos oficiales de la ciudad en un momento en que la capital del imperio comenzó a exportar piezas muy representativas del arte augusteo con un marcado carácter neoático, presente en los fragmentos aquí analizados.
\end{abstract}

Palabras clave. Altar; teatro; Córdoba romana; importación.

\begin{abstract}
We address the study of four pieces that are currently in three different places (the Archaeological Museum of Cordova and private collections), but which surely once were part of a single altar from the Augustan-Tiberian period in Roman Cordova. We present a detailed analysis of its characteristics, both in style and technique, while other possible functions (specifically that of a pedestal) have been discarded to give it an altar function. In order to facilitate the understanding of its characteristics, we have fitted a model with the four fragments. Its rich thematic richness, characteristics of workmanship, style and dimensions, as well as the localized parallels, support the theory of an importation from the capital of the empire in the first half of the $1^{\text {st }}$ century AD, like other pieces from this city. This altar would have been made of different pieces to be assembled in situ and that we believe would be part of the decoration of a monumental building, probably the theater, due to its close connection with Dionysios. The virtual restitution of the altar shows a very peculiar type for these elements, without exact parallels known so far. Therefore, the capital of the Baetica province confirms for this period a direct trade of pieces of extraordinary quality destined to embellish the official buildings of the city, at a time when the capital of the empire began to export pieces that are highly representative of Augustan art with a marked neoatic nature, as can be seen in the fragments analyzed here.
\end{abstract}

Key words. Altar; theater; Roman Cordova; import.

\footnotetext{
Financiación: Título del proyecto: Corduba renace de sus fondos: claves de interpretación virtual de la Córdoba romana, financiado por el Programa Logos, Fundación BBVA de Ayudas a la Investigación en el Área de Estudios Clásicos. Agradezco las facilidades prestadas por parte del Museo Arqueológico de Córdoba, en especial a su directora, Doña María Dolores Baena, sus conservadores, $\mathrm{D}^{\mathrm{a}}$ María Jesús Moreno, D. Alberto Montejo y D. José Escudero y a los funcionarios encargados de los almacenes, Da Juana Izquierdo y D. Miguel Muñoz. Del mismo modo, sus conclusiones han sido posibles gracias al proyecto Vivere in urbe. Arquitectura residencial y espacio urbano en Corduba, Ategua e Ituci. Investigación y socialización (PID2019-105376GB-C43) del Ministerio de Ciencia e Innovación. En algunos apartados de este artículo colaboró el prof. Antonio Peña pocos meses antes de su fallecimiento. Mi homenaje a su memoria y a su obra que van en paralelo a mi admiración y tristeza por su pérdida.
} 

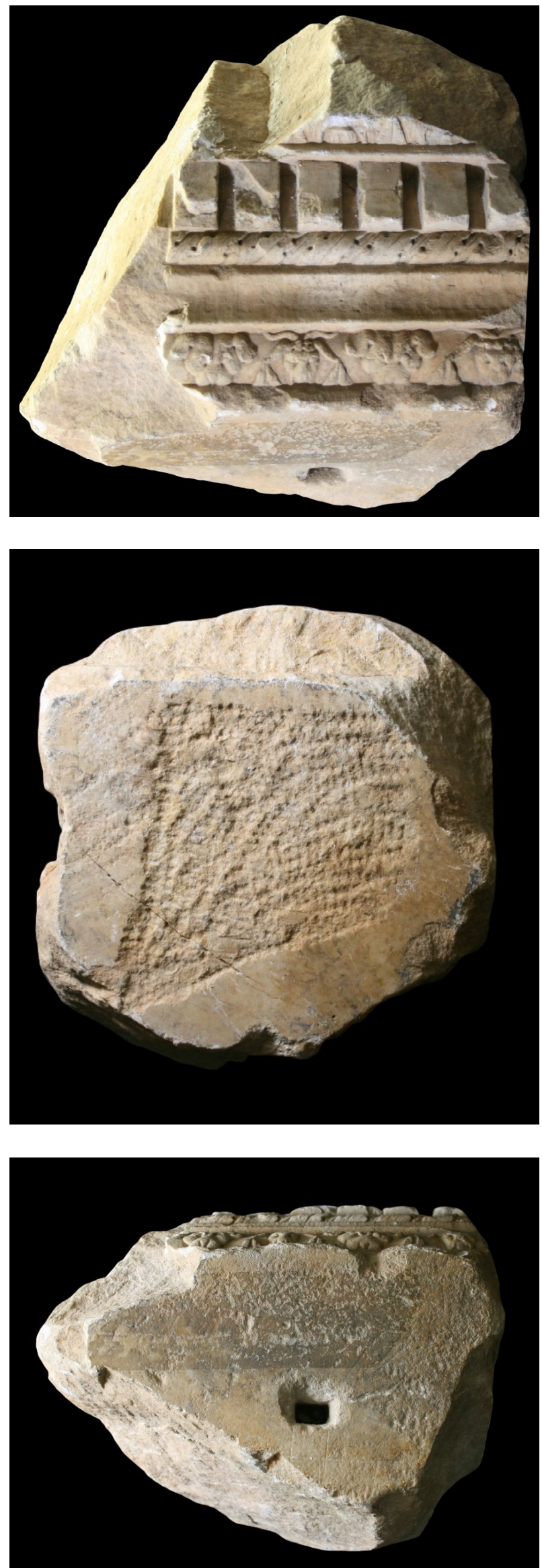

Figuras 1-3: Fragmento de cornisa del Museo Arqueológico de Córdoba. Fotografías: autor
Dentro de un amplio proyecto que tiene por objetivo el estudio del material arquitectónico depositado en los almacenes del Museo Arqueológico de Córdoba, se ha localizado una pieza (Número 1.1) que cuenta con unas características ornamentales muy definidas que la vinculan, como veremos más tarde, a otras tres piezas (dos publicadas, la otra inédita) de diversa procedencia pero que pertenecerían todas ellas a un mismo objeto muy señalado de la Córdoba romana. La calidad de la que hacen gala estos fragmentos unida a la tipología y características del elemento-base al que pertenecieran hacen necesarias unas reflexiones que concluirán con una propuesta acerca de su tipología, cronología, origen y localización.

\section{PIEZAS EN ESTUDIO}

\subsection{Fragmento de cornisa (Figs. 1-3)}

Dimensiones: Altura máxima: $21,3 \mathrm{~cm}$; profundidad máxima: $13,4 \mathrm{~cm}$.

Material: Mármol blanco de grano fino de similar tamaño y cristalino, probablemente Carrara (Lapuente y Álvarez, 2012: 82).

Estado de conservación: Rota por la zona superior y el lateral izquierdo.

Bibliografía: Inédita.

Localización: Museo Arqueológico de Córdoba (Número de Registro: 28476)

Fragmento de cornisa elaborada en mármol blanco de grano fino. Está decorada en una de sus caras (Fig. 1) con distintas molduras, siendo desde abajo hacia arriba: listel liso, un óvolo o cuarto bocel decorado con cabezas de cabra que se alternan con otras de felino (¿pantera?) las primeras de las cuales apoyan sus orejas en lo que parecen los extremos de hojas lisas de forma triangular; diversos toques de trépano en puntos de dichas cabezas; por encima, un caveto liso, otro pequeño listel liso y un pequeño óvolo decorado con una sucesión de hojas dispuestas en diagonal con dirección hacia la derecha del espectador, marcadas por una hendidura central y con numerosos orificios de trépano que separan las hojitas; por encima un denticulado y el arranque de una moldura (con toda probabilidad en cyma recta), fragmentada, de la que sólo se conservan algunas hojas triangulares separando motivos que no podemos definir por su estado de conservación.

La pieza está rota, como hemos dicho, por el lateral izquierdo y por la parte superior, en la zona de arranque de una de las molduras de la zona superior; el lateral derecho cuenta con una zona de anathyrosis en forma de rombo que facilitaría el ensamblaje con la pieza de al lado (Fig. 2); la cara que sirve de base (Fig. 3) tiene un orificio para anclaje y a su lado unas líneas-guía que se han hecho para señalar las dimensiones y ubicación exactas de dicho orificio que es rectangular de 25 por $14 \mathrm{~mm}$; la cara superior tiene otro orificio para perno 
de 20 por $30 \mathrm{~mm}$ y un canal de $60 \mathrm{~mm}$; en una de las caras rotas tiene escrito: C.M. 21-11-74. N.R. 28476.

Una de las molduras decoradas de esta pieza, en concreto la que representa la secuencia de cabezas de cabras y felinos tiene idénticos motivos y características que los que aparecen en dos pilastras conocidas (véase infra piezas 1.3 y 1.4) y publicadas, que a partir de ahora podemos vincular con esta cornisa.

\subsection{Fragmento de CORnisa (Fig. 4)}

Dimensiones: Según la página web (https://www. jbagot.art/obra/fragmento-de-cornisa), su altura es de $31 \mathrm{~cm}$. Pero la medición correcta de la cornisa depositada en el Museo (supra, número 1.1) indica que la altura real podría ser de $21,3 \mathrm{~cm}$ y que la medida arriba indicada se ha tomado con la disposición que indica la figura 4.

Material: Con toda probabilidad, mármol blanco. No se ha podido hacer la autopsia de esta pieza por lo que ni la información referida a las dimensiones ni la composición del mármol pueden ser comprobadas.

Estado de conservación: Aunque no hemos podido verla directamente, tiene rota la parte superior y los dos laterales.

Bibliografía: Inédita. Su fotografía y descripción en https://www.jbagot.art/obra/fragmento-de-cornisa

Localización: Colección particular

Hace algún tiempo, un colega llamó mi atención sobre una cornisa que aparecía a la venta en un negocio de objetos de $\operatorname{arte}^{1}$; la pieza tenía interés no solamente por su calidad sino además por el hecho de proceder de Córdoba y por tener idéntica decoración que nuestra pieza número 1.1 con la diferencia de que este fragmento desarrolla casi toda la cornisa y en consecuencia, amplía nuestro conocimiento sobre su imagen, forma y significado.

Fragmento de cornisa elaborada en mármol blanco; la secuencia de molduras y decoración es similar a la pieza número 1.1, por lo que no la repetimos aquí; por encima del denticulado, última moldura completa de la primera cornisa, se desarrolla otro óvolo en el que se alternan máscaras parece que de Sileno y Pan y hojas triangulares para separar estos motivos; la última moldura es una cima recta con un anthemion de palmetas y cálices de hojas lisas, elementos ambos que nacen a su vez de otros cálices enlazados por estrechos lazos. Es reseñable destacar que la dirección diagonal de las hojas de la moldura central no adopta la dirección hacia la derecha como sucedía en la pieza antes vista, sino hacia la izquierda.

1. https://www.jbagot.com/obra/fragmento-de-cornisa Según dicha página web, la pieza se conserva en poder de la colección de Francisco A. C. Mohedano, de Córdoba, que la adquirió en 1970.

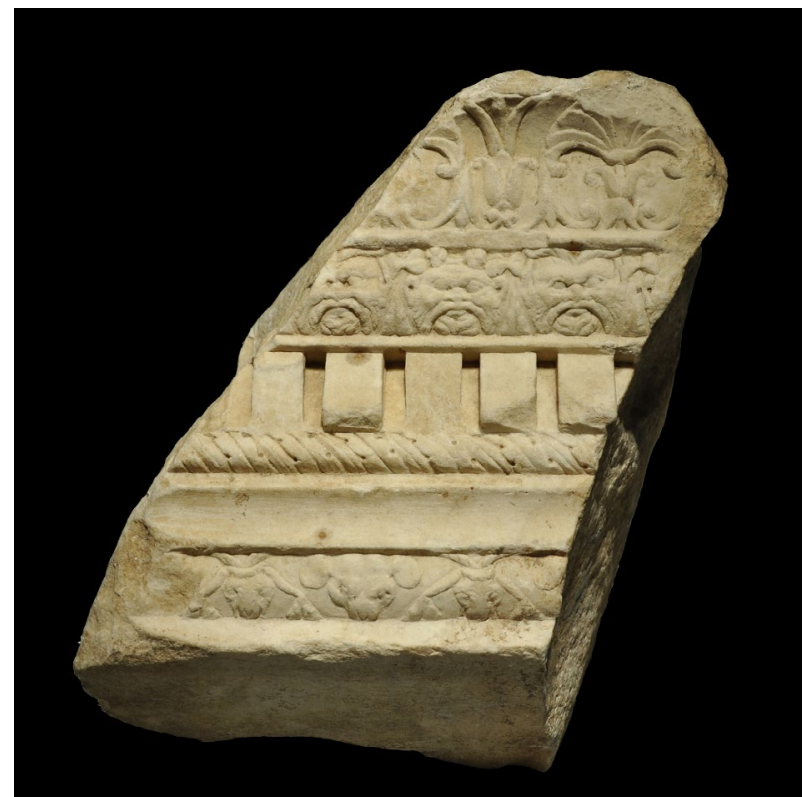

Figura 4: Fragmento de cornisa. Colección particular. Fotografia: https://www.jbagot.art/obra/fragmento-de-cornisa

\subsection{Fragmento de Pilastra heXagonal (Figs. 5-7)}

Dimensiones: Excepto la altura $(12,5 \mathrm{~cm})$, similares a la pieza 1.4 (véase infra).

Material: Mármol blanco de grano fino de similar tamaño y cristalino, probablemente Carrara (Lapuente y Álvarez, 2012: 82).

Estado de conservación: erosionada en distintas zonas y rota por su cara superior e inferior.

Bibliografía: Santos Gener, 1955: 84 s., fig. 39; Hesberg, 1996: fig. 24-a; Márquez, 1998: cat. 328, 124, 174 y fig. 4.3, lámina 8; Márquez, 2004: 341 s., fig. 5. Localización: Museo Arqueológico de Córdoba (Número de Registro 9466).

Esta pilastra tiene, como hemos visto, una forma hexagonal contando con dos caras lisas (Fig. 5) y las otras decoradas (Figs. 6 y 7), introduciendo algunas molduras de separación tanto lisas como decoradas, dos de las cuales tienen motivos de cabezas de cabra y felino similares a los de las piezas 1.1, 1.2 y 1.4. La decoración vegetal consiste en un tallo que forma el eje de la composición del que van naciendo flores y cálices con similares características de estilo a las que veremos en la pieza siguiente y cuyos paralelos remiten a un periodo augusteo, tema que más adelante ampliaremos.

En 1998 y dentro de un estudio sobre la decoración arquitectónica romana en Córdoba se analizó esta pieza (Márquez, 1998: cat. 328, 124, 174 y fig. 4.3 y lámina 8) datándola en el periodo augusteo y planteando como hipótesis su pertenencia a la esquina de un altar (Márquez, 1998: 124 y 174), información que se amplió más tarde en otra publicación donde ya se mencionaba la existencia de otro fragmento (número 1.4, infra), perteneciente a esta misma pilastra hexagonal (Márquez, 2004: 341 y s., fig. 5). 

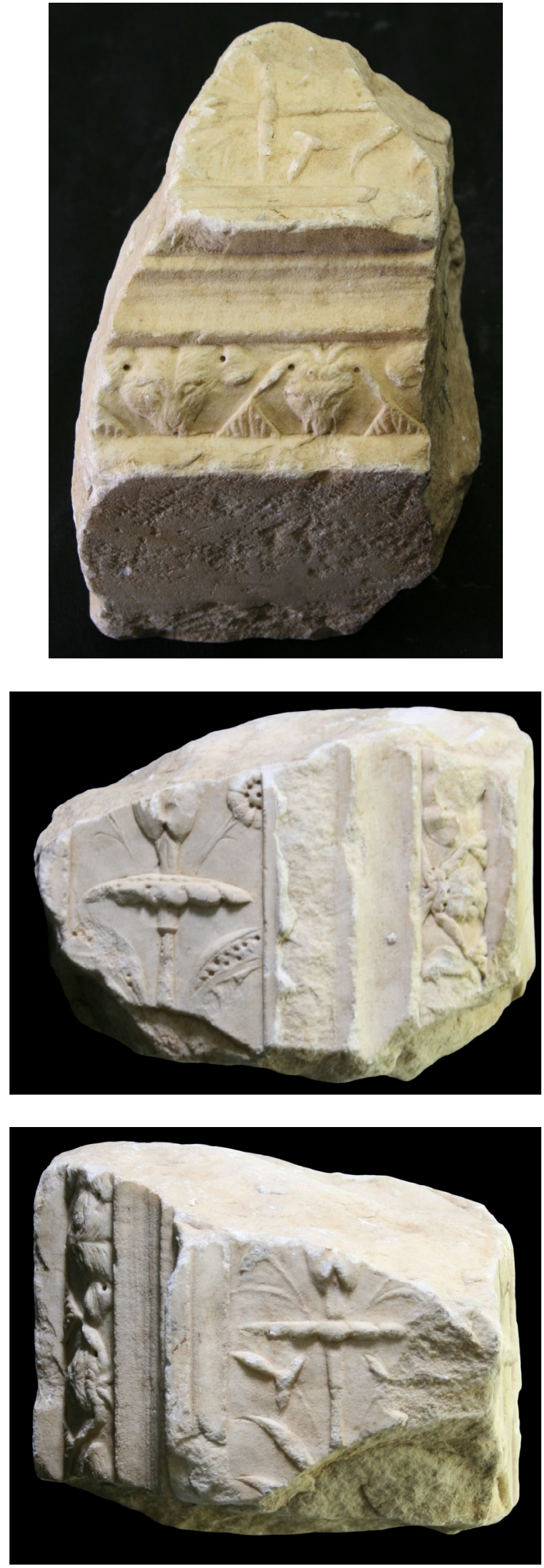

Figuras 5-7: Fragmento de pilastra: Museo Arqueológico. Fotografías: autor

\subsection{Fragmento de Pilastra heXagonal (Figs. 8-10)}

Dimensiones: Altura máxima: $12,2 \mathrm{~cm}$; anchura máxima: $17 \mathrm{~cm}$; profundidad: $17 \mathrm{~cm}$.

Material: Mármol blanco de grano fino de similar tamaño y cristalino, probablemente Carrara (Lapuente y Álvarez, 2012: 82).

Estado de conservación: Erosionada por la parte inferior y rota por la superior; algunas zonas están muy deterioradas por desgaste y algunas zonas están grises por posible contacto con el fuego.

Bibliografía: Márquez, 2004: 341 s., fig. 5.

Localización: Colección particular Córdoba.

Se trata de una pilastra hexagonal con cuatro de sus caras decoradas y otras dos lisas; una zona de la pieza, sin trabajar (líneas en rojo en la figura 10), semejante en todo a la pieza antes vista; serviría para adornar la esquina de otra pieza de mayor tamaño que bien podría ser un altar o pedestal, como tendremos ocasión de comentar más adelante; si comenzamos la descripción a partir de la cara lisa, nos encontramos con una moldura lisa (color verde) de $6,5 \mathrm{~cm}$ en cuya zona inferior tiene parte de un orificio para perno de 2 por $2 \mathrm{~cm}$ y una profundidad de $1 \mathrm{~cm}$; la siguiente moldura es un óvolo decorado con cabezas de cabra que se alternan con otras de felino (¿pantera?) las primeras de las cuales apoyan sus orejas en lo que parecen los extremos de hojas lisas de forma triangular; diversos toques de trépano en puntos de dichas cabezas; a su lado, un caveto liso y un ancho listel que enmarca uno de las dos caras decoradas con un motivo de candelabro vegetal; a su lado tiene una moldura (por lo poco que se conserva se trataría de un caveto y listel) que haría esquina pero que no se ha conservado y que serviría de marco a su vez para el segundo panel decorado con un motivo parecido al primero; a su lado, un caveto y listel cuya superficie está muy deteriorada y no se ha conservado el motivo ornamental que llevase; después, un caveto liso y de nuevo un óvolo con la misma decoración de antes en el que se alternan cabezas de animales; finalmente otra franja lisa para adosar (color verde) otra placa.

Debemos detenernos un momento en las dos caras decoradas (color azul) que tienen un motivo idéntico con pequeñas variantes; en la primera de ellas y sobre un elemento poco claro pero que con toda probabilidad sería una hoja de acanto, se despliega el motivo central que consiste en un cáliz vegetal formado por dos hojas que se juntan por la base y se abren en la parte superior; en el eje nace un tallo que se levanta en vertical y que será el eje de toda la composición; las hojas del cáliz conservado son de una plasticidad extraordinaria, con mayor relieve en la base y más pegado a la superficie en los laterales. La zona inferior está alisada en una estrecha banda, por lo que creemos que ésta sería la zona de arranque del motivo y, en consecuencia, este fragmento sería el que ocuparía la parte inferior de la pilastra. La otra cara decorada cuenta con similares 
características ornamentales, con el añadido de dos flores cuyos delgadísimos tallos nacen del interior del cáliz y que cuenta con muchos toques de trépano; el tallo en su mitad inferior está cubierto de dos hojas.

Una vez analizadas las cuatro piezas objeto de estudio, comenzamos un estudio de las diversas cuestiones vinculadas al estilo, función y cronología de la pieza a la que perteneciesen estos cuatro fragmentos.

\section{ANÁLISIS DE LAS PILASTRAS}

Dos de nuestras piezas (números 1.3 y 1.4, Figs. 5-10) son pilastras hexagonales decoradas con motivos animales y vegetales. Las pilastras vegetales fueron objeto de una fundamental investigación gracias al trabajo de M. Mathea-Förtsch (1999), a quien remito para más información; se trata de elementos de gran riqueza ornamental nacidos y desarrollados al calor de las nuevas concepciones artísticas del periodo augusteo y que fueron empleadas de forma masiva tanto en ámbito público como privado. Aunque con una tipología amplia de motivos y formas, destacan los vegetales por encima de cualquier otro, con motivos sobre todo de candelabro (como es nuestro caso) o de roleos acantiformes; respecto a las formas, las pilastras que más abundan son las de sección rectangular o triangular (menos frecuente) aunque también se conocen casos de secciones con más lados como el ejemplo de pilastras poligonales de cinco lados (Mathea-Förtsch, 1999: cat. 241, Taf. 18). Sin embargo, no hemos encontrado paralelos para pilastras hexagonales como la que estudiamos aquí.

Desde un punto de vista tipológico, los relieves vegetales de nuestras pilastras entrarían dentro del tipo conocido como «candelabro» (Mathea-Förtsch, 1999: 10-14) mientras que P. Pensabene lo incluye en el grupo de piezas con tallo central estrecho (Pensabene, 1982: 152 ss.); para este investigador, la amplia producción atestiguada en Cherchel se explicaría como importación de Roma o de Ostia o bien serían el producto de talleres romanos en aquella localidad africana, cuestión que, aplicada al caso de Córdoba, analizaremos más adelante.

No son éstas las únicas representantes de este tipo de elementos en la Córdoba romana, pues su presencia se documenta por primera vez con estas piezas de clara cronología augustea como tendremos ocasión de demostrar más adelante; poco después se detectan otras piezas que pueden datarse a finales del periodo augusteo o ya tiberiano (Márquez, 1998: 124, cat. 142145; Mathea-Förtsch, 1999: cat. 49, Taf. 100,5) muy probablemente también importadas; en un momento posterior, tal vez adrianeo, se documenta por primera vez una pilastra de sección triangular elaborada por talleres locales (Márquez, 2004: 350, fig. 20) que copian modelos urbanos: en el caso que citamos, los paralelos con algunas piezas elaboradas para decorar Villa Adriana son evidentes (Mathea-Förtsch, 1999:
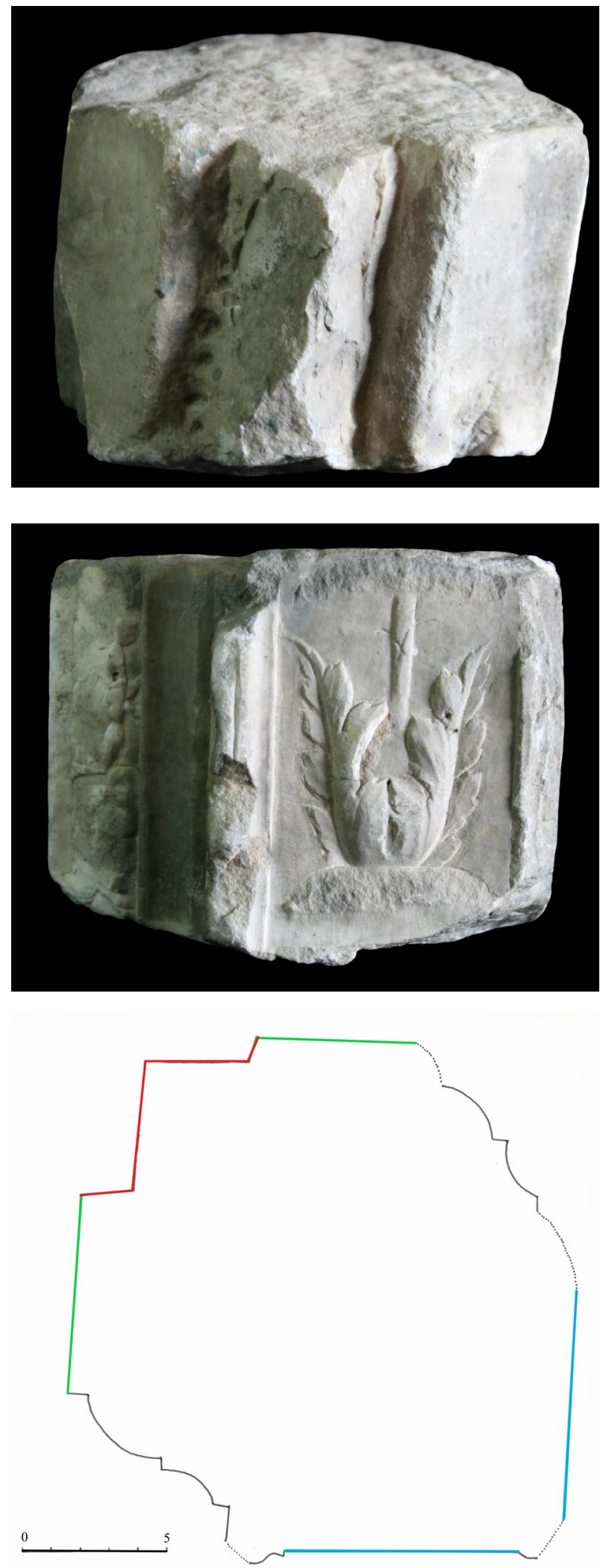

Figuras 8-10: Fragmento de pilastra y sección. Colección particular. Fotografías y dibujo de sección: autor

cat. 243, Taf. 99). Todo ello demuestra el empeño por parte de quienes empleasen estas cornisas en seguir fielmente los modelos ornamentales imperantes en la capital. 
Su sección hexagonal las convierte en elementos muy peculiares por la falta de paralelos; a la particular sección de seis caras se une el hecho de que dos de ellas están destinadas a ser empotradas para formar la esquina de un elemento todavía por definir; algo parecido podemos apreciar en una pieza que actúa como pilastra de esquina (Mathea-Förtsch, 1999: cat. 236, Taf. 16, 3-4) de un monumento cuya reconstrucción como altar resulta, de momento, indemostrable. De cualquier modo, lo que diferencia nuestras piezas de otras conocidas, además del número de caras, estriba en el hecho de ir empotrada al elemento original al que perteneciese, o sea, que no se labró toda la pieza en un solo bloque, tema que retomaremos al hablar de cuestiones de técnica.

\section{ANÁLISIS DE LAS CORNISAS}

La decoración de los dos fragmentos de cornisa (Números 1.1 y 1.2, Figs. 1-4) resulta del máximo interés dada la poca frecuencia con que diversos elementos tanto vegetales como animales monopolizan la ornamentación de casi todas las molduras; obviamente nos hallamos frente al empleo de figuras y representaciones vegetales y animales como parte de un lenguaje simbólico destinado a lanzar un mensaje (Sauron, 1982: 702); y como tendremos ocasión de ver más adelante, la vinculación de lo aquí representado con un ambiente dionisiaco, más que directamente con el dios, resulta evidente.

Desde la base de las cornisas hacia arriba, la primera moldura es un óvolo decorado con cabezas de felino (¿pantera, leopardo?) y cabras, estas últimas apoyando sus orejas en unas hojas de marcada forma triangular; se trata de dos animales frecuentemente representados en el cortejo báquico, pero que también están vinculados a un ambiente campestre e idílico (Toynbee, 1996: 82 ss. y 165 ss.; Meilán, 2013).

La siguiente moldura decorada es otro óvolo con una sucesión de hojas de difícil adscripción, tal vez de acanto; es bien sabido que el monopolio que algunos elementos vegetales ejercen dentro del orden clásico en la arquitectura romana se produce por primera vez en época de Augusto (Zanker, 1992: 120, 217 ss.) por lo que tal vez sería bueno recordar la masiva presencia del elemento vegetal en el templo de Apolo Sosiano (Viscogliosi, 1996: 59 ss.) y otros ejemplos a él contemporáneos. En nuestro caso, estas hojas actúan a modo de cintas similares a las que decoran diversos altares y urnas funerarias como elementos de separación de temas y/o molduras pero que, claramente, aumentan de forma considerable el objetivo simbólico de introducir la naturaleza en las escenas representadas (Dräger, 1944: Kat. 44, Taf. 34 s. y Kat. 45; Sinn, 1987: Kat. 53, 64, 71, 79).

Por encima del denticulado se desarrolla otra moldura en forma de óvolo en la que alternan máscaras dionisiacas de Pan y Sileno con las características propias de estos personajes como son la edad madura y los mofletes carnosos; véase la similitud de una de estas máscaras con un herma doble hoy conservado en una colección de Bayreuth (Grassinger, 2008: 160 s.); al igual que en la moldura inferior, unas hojas de marcada forma triangular separan cada uno de estos motivos; las máscaras en general y, como en nuestro caso, las dionisiacas en particular son empleadas como elementos ornamentales recurrentes tanto en la decoración privada como en ámbito público; al respecto, diversos estudios ponen de relieve la vinculación de estos elementos con Dionysos y su empleo en el periodo griego, helenístico y romano en muy diversos ámbitos (Lo Monaco, 2010: 106 y 113). Un ejemplo del empleo de este recurso ornamental en elementos de culto nos lo proporciona el altar circular de Pistokrates y Apolodoros, datado en el último cuarto del siglo II a. C., y decorado con máscaras que sostienen una guirnalda, procedente del Santuario de Dionysos Eleuthereus en Atenas (Heinemann, 2011: 394, fig. 2, plate LV).

Como parte de la decoración arquitectónica, la presencia de las máscaras se atestigua desde el periodo helenístico si bien su uso se confirma en casi todo el periodo imperial (Rumscheid, 1994: 294 s.; Heinemann, 2011), muy especialmente en la parte oriental del imperio: véase el ejemplo del friso del propylon del Sebasteion de Afrodisias, dedicado a Afrodita y a la familia imperial julio-claudia y donde aparecen varias máscaras dionisiacas como las estudiadas en este trabajo (Chaisemartin, 2006: figs. 4b, 5, 8, 10 y 14, 63-67).

Se trata, como vemos, de un motivo muy presente en muy diversos ambientes, al que debemos de sumar el privado; este apartado se vio perfectamente documentado con el trabajo de H. U. Cain (1988) donde estudia este tipo de máscaras representadas en oscilla y otros tipos de relieves de ámbito doméstico, similar ambiente al que pertenecería una copa de cerámica vidriada con máscaras de Pan (Fallmann, 2015); y también doméstico, pero en este caso funerario, podemos mencionar ejemplos como pone de manifiesto el altar de Maemptus (Boschung, 1993: 38, Taf. 12, 1-2).

Será sobre todo en los elementos de adorno de gran riqueza ornamental desarrollados por los talleres neoáticos en Roma donde Dionysos y su corte alcancen una espléndida representación (Heinemann, 2011: 391); así por ejemplo en las cráteras de mármol, donde no solamente están presentes como motivos ornamentales durante todos los periodos, sino que también dan sustento a muchas de las asas de dichos elementos (Grassinger, 1991: 40 ss.; 53 ss.; 218 ss.), además de protagonizar dichas máscaras todo el espacio disponible en algunas de las piezas analizadas como es el caso de una crátera conservada hoy en París y otra pieza en Tarragona (Grassinger, 1991: 42 y fig. 227). Idéntico panorama encontramos en el caso de los candelabros de mármol (Cain, 1985: 107 s., 122 s., Beilage 6, 9-13); resulta interesante observar la presencia de pequeños frisos como coronamientos del cuerpo central en algunos candelabros que cuentan con una disposición de máscaras alternas similares a las presentes en nuestra moldura aunque más separada y con más elementos 
vegetales como elementos de separación (Cain, 1985: Kat. 71, 124 y 127); casos similares encontramos en los altares (Dräger, 1994: 96 ss.) donde algunas máscaras protagonizan escenas con motivos vegetales (Dräger, 1994: Kat. 36, Taf. 80, 1-2) o bien en algunos puteales (Golda, 1997: 52 ss.; 42 s.; Beilage 6 ss.); y finalmente, idéntico discurso puede hacerse con respecto a algunas urnas de mármol (Sinn, 1987: Kat. 2, 264, 433, 75 s.). No debemos olvidar que obra de escultores neoáticos en Roma serían las máscaras colosales que, con un marcado carácter ornamental, había mandado hacer Augusto para adornar las claves de algunos arcos del teatro de Marcelo (Chaisemartin, 2006: 74), modelos que podrían pasar como motivos dentro de estos talleres a decorar los elementos arriba mencionados.

Este motivo abunda también en la pintura, donde puede aportarnos una destacada información al respecto: en la Casa de Augusto en el Palatino se encuentra la estancia 5, también conocida como «Sala delle Maschere» donde están presentes además de máscaras de diversas clases una serie de paisajes sacro-idílicos que remiten a la aurea aetas y a diversos santuarios (Sauron, 1994: 587-592).

La moldura que decora el remate superior no está completa, pero a pesar de ello permite conocer el motivo en anthemion formado por palmetas de hojas de loto y cálices de hojas lisas, motivos de clara filiación augustea como veremos más adelante y que encuentra buenos paralelos en el Ara Pacis y el Foro de Augusto (Leon, 1971: Taf. 140,1, 262 y 278). Resulta interesante que sean hojas de loto y no palmetas las que aparezcan en nuestro relieve con las hojas más ornamentales; ello llevaría a vincular muy directamente esta ornamentación con Egipto, dentro de una búsqueda de lo exótico por parte de una parte de la sociedad romana amante de estas imágenes que buscarían de forma premeditada esta elección distintiva de otras corrientes estéticas más estandarizadas (Salvetti, 2020: 75); en esa misma línea de relacionar estos relieves con elementos ornamentales de origen egipcio y a la misma sala citada con anterioridad de la Casa de Augusto pertenecen algunos motivos interpretados por diversos investigadores como vinculados a Egipto, como por ejemplo la cornucopia doble o dikeras (León, 2020: 90 s.; Sauron, 1994: 587-592)), razones todas ellas que nos inducen a pensar en un posible influjo ornamental de origen alejandrino-tolemaico. Tampoco debemos de olvidar de qué modo las hojas de loto se emplean como atributos vinculados con la divinidad en algunas esculturas del periodo tolemaico, como bien ha demostrado E. La Rocca en un reciente trabajo (2021: 117-132).

\section{TÉCNICA}

Es fácilmente observable la calidad de los relieves resultado de una técnica muy depurada, tema que retomaremos más adelante; ahora interesa destacar diversas características de estos fragmentos que nos están indicando que estamos ante un objeto realizado en diversas piezas que se ensamblarían, con toda probabilidad, en el lugar de destino. Para facilitar este último proceso se han realizado diversos orificios para el encaje de pernos: a modo de ejemplo, la cara posterior de nuestra pieza 1.1 tiene un hueco rectangular $(60 \mathrm{~mm}$ de largo por $30 \mathrm{~mm}$ de ancho el canal y el orificio tiene $20 \mathrm{~mm}$ de ancho) que servía para la colocación de un perno que lo unía a la pieza que tenía al lado; la unión se haría mediante un perno en forma de $\Pi$; para facilitar su ensamblaje, el lateral cuenta con anathyrosis (Fig. 2), es decir, una superficie picada en forma de rombo más hundida que las superficies alisadas del contorno.

La cara de apoyo de este mismo fragmento, por su parte, cuenta con un orificio rectangular de anclaje para cuya realización se han trazado una serie de líneas-guía (Fig. 3).

El acabado de las distintas caras es otra cuestión a destacar porque corrobora la función que creemos darle a cada una de ellas; las dos caras interiores (de color rojo en la figura 10) estarían pegadas a dicho elementobase, razón por la que su superficie no está alisada; por su parte, las caras en donde debían juntarse las placas decorativas del elemento-base están alisadas (de color verde en la figura 10) para facilitar la unión con otras placas.

\section{ENSAMBLAJE}

Con toda esta información de carácter técnico estamos en disposición de ensamblar, aunque sea de manera teórica y virtual, los distintos fragmentos aquí analizados; queda claro que se deben emparejar las dos pilastras (Fig. 11), que pertenecerían a la misma o distinta pieza, y los dos fragmentos de cornisa; estas últimas no plantean problema alguno de ubicación, aunque sí de conexión y ello porque las molduras vegetales presentes en las dos piezas tienen direcciones diversas, por lo que sería oportuno pensar que no conectaban entre sí y probablemente cada una de ellas se encontrara en un lado del elemento-base separados por el eje de la pieza donde se ubicasen (o bien se hallaban en lados distintos del objeto en estudio); la clave para situar las pilastras viene dada por la zona no labrada que existe entre las dos molduras lisas; se trata de un saliente esbozado en forma de W (Figs. 8 y 11) que serviría para empotrar en el cuerpo del elemento-base al que perteneciese, elemento que necesariamente debía ser cuadrado o rectangular dado que las caras lisas que servían para empotrar las placas de recubrimiento están dispuestas formando un ángulo recto: la anchura de estas dos caras lisas de la pilastra no es idéntica: una mide $5,5 \mathrm{~cm}$ y la otra $6,5 \mathrm{~cm}$, lo que nos indica que la anchura de las placas adosadas a ella y que recubrirían el elemento base en sus cuatro lados debían de tener esta misma anchura; ello es importante porque nos confirma que dicho elemento base tenía que ser macizo con toda seguridad por dos razones; la primera, porque así 


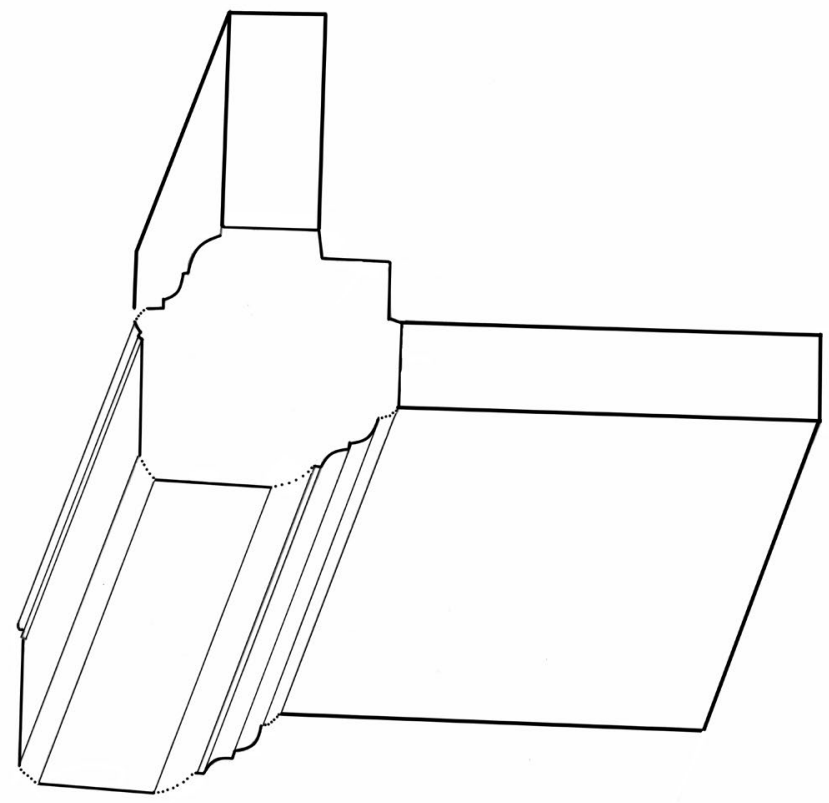

Figura 11: Modo de encaje de las pilastras. Dibujo: autor

lo indica la cara no labrada de la pilastra con esa forma en $\mathrm{W}$ para empotrarse con un cuerpo interno; pero además, porque la cornisa que corona este elemento (piezas 1.1 y 1.2) tienen una profundidad mínima de $13,4 \mathrm{~cm}$, lo que imposibilita que una placa de 5,5 o de $6,5 \mathrm{~cm}$ de anchura pueda sustentarla. Este dato es de crucial importancia porque define un elemento-base macizo al que se le aplicarían los distintos elementos (pilastras, cornisas, placas de revestimiento, basas). No estaríamos, en consecuencia, ante un recinto arquitectónico o bien un elemento hueco.

\section{DIMENSIONES}

Aunque no disponemos de ningún elemento completo que nos pueda facilitar algún tipo de ayuda para conocer las dimensiones completas del elemento-base, hemos hecho un pequeño estudio acerca de la proporción entre anchura y altura de las placas completas que menciona M. Mathea-Förtsch en su trabajo (1999) y hemos sacado en conclusión que el módulo ancho-alto es, aproximadamente, de 4 a 6; la anchura de nuestras pilastras es de $17 \mathrm{~cm}$, lo que hace que su altura, naturalmente sin base y sin coronamiento, oscile entre los 70 a los $100 \mathrm{~cm}$. Para facilitar la tarea, podemos pensar en la media de ambas medidas, es decir, de $85 \mathrm{~cm}$. A esta altura tendríamos que sumar la correspondiente a la hipotética base que tuviera este elemento, sobre la que más adelante hablaremos pero que podemos cifrar en unos $12-15 \mathrm{~cm}$ y, naturalmente, la altura de la cornisa que sí conocemos y que tiene $21,3 \mathrm{~cm}$; con todo ello la altura total del elemento sería aproximadamente de 120 $\mathrm{cm}$, es decir, unos cuatro pies (Figs. 12 y 13).

Sobre la anchura no tenemos elementos suficientes para plantear hipótesis.

\section{CRONOLOGÍA}

Ya fue planteada en su día una cronología augustea para las pilastras hexagonales (Márquez, 1998: 62, 124 y 174, notas 78-81), y las nuevas piezas no hacen más que confirmar dicha cronología; si siguen siendo válidos los paralelos augusteos para sus motivos vegetales, algunos de los relieves que ahora conocemos gracias a las nuevas piezas presentadas redundan en dicha cronología: el anthemion que corona la pieza 1.4, muy similar al que adorna la Sala del Coloso del Foro de Augusto (Leon, 1971: Taf. 140,1; Ungaro, 2004: 30, fig. 20) o bien sirven también de paralelo los paneles de separación de los relieves internos del Ara Pacis.

Podemos añadir, como confirmación a la cronología planteada, la similitud de estilo que respiran nuestras piezas, sobre todo los frisos figurados, con algunos candelabros augusteos cuya decoración cuenta con similares máscaras que en nuestro caso (Cain, 1985: cat. 71 , Taf. 32,1; 33,1) en los que el trépano, mediante orificios muy delgados se emplean en todos los elementos vegetales. Similar modo de actuar es el que se observa en la decoración vegetal de los conocidos «Relieves Grimani» en los que dicha técnica se aplica de forma profusa, en concreto dando a las flores un resultado semejante al nuestro; confróntese en este sentido el relieve de la leona y véanse las dos flores que tiene junto a su cabeza, que son idénticas a las de la pieza cordobesa (Agnoli, 2013: 248 s.).

\section{FUNCIÓN}

Llega la hora de intentar darle una función a nuestros fragmentos; S. de los Santos Gener, quien publicó por primera vez la pilastra número 1.3 (Santos Gener, 
1955: 84) opinaba que se trataba de un fragmento de puerta, función que no podemos compartir dado que no responde a la tipología de dinteles y, además, porque entonces sólo tendría sentido una de las dos caras alisadas (en color verde en la figura 10) que serviría para empotrar con el muro; ni tan siquiera estamos ante el hipotético cierre de un recinto similar al localizado en Terni (Mathea-Förtsch, 1999: Kat. 238, Taf. 16,3-4 y 17,1) dado que la otra cara alisada de la pieza cordobesa no estaría adosada a ningún muro.

Desechada, pues, una función como puerta, toca pensar para qué podría servir un elemento de aproximadamente 1,20 metros de altura, como tuvimos ocasión de comentar en párrafos anteriores; llegamos así a dos posibles funciones muy ligadas entre sí: pedestal o altar; entre ambas posibilidades nos decantamos por elegir la segunda de ellas por varios motivos; en primer lugar, la tan rica como recargada decoración presente es mucho más propia de altares que de sencillos pedestales; en segundo lugar y desde un punto de vista formal, hay dos modelos de altar en los que pueden encajar nuestras piezas siempre teniendo en cuenta sus especiales características; en el estudio que O. Dräger hace de estos singulares elementos distingue varias tipologías dentro de las cuales menciona el Grupo I, A (Dräger, 1994: 31-37) formado por altares rectangulares (Rechteckige Aren) a los que se le aplican las placas relivarias en forma de friso; esta podría ser una solución perfecta para nuestras piezas que, como hemos visto, están hechas para recubrir y empotrarse en un bloque.
Al respecto, menciona O. Dräger (1994: 32 ss.) que son piezas de alto contenido religioso cuyos relieves copian opera nobilia, con modelos proporcionados por altares del periodo arcaico al clásico ampliando a otros ámbitos como el funerario a partir del siglo IV; durante el periodo tardorrepublicano e imperial también se hicieron pedestales y altares macizos revestidos con relieves, entre los que destacan el Ara Pacis y el altar del templo de Vespasiano en Pompeya (Dräger, 1994: 34). Al respecto este investigador menciona dos ejemplos entre los que destaca el relieve hoy conservado en la Galería Borghese (Dräger, 1994: 32, Kat. 49, Taf. 8,1-3 y 9,1) de temática dionisiaca y donde están presentes todos los personajes del thiasos báquico representados en las piezas cordobesas.

Pero las características de nuestras piezas permiten pensar en otro tipo de altares, también conocidos por este investigador alemán como «toreutische Form» (Dräger, 1994: 45 ss.); efectivamente, al periodo augusteo se adscribe el comienzo en la producción de este tipo de piezas elaboradas en mármol con una decoración que adopta un sabor metálico muy acentuado en sus relieves y algunas formas caprichosas, algo que encaja perfectamente en nuestros cuatro fragmentos, especialmente en las pilastras; es cierto que los ejemplos proporcionados por O. Dräger para este segundo tipo presentan una realización en bloque y no, como vimos en párrafos anteriores al referirnos a la primera tipología, en piezas sueltas; ello podría explicarse con dos ideas que debemos de considerar a continuación:

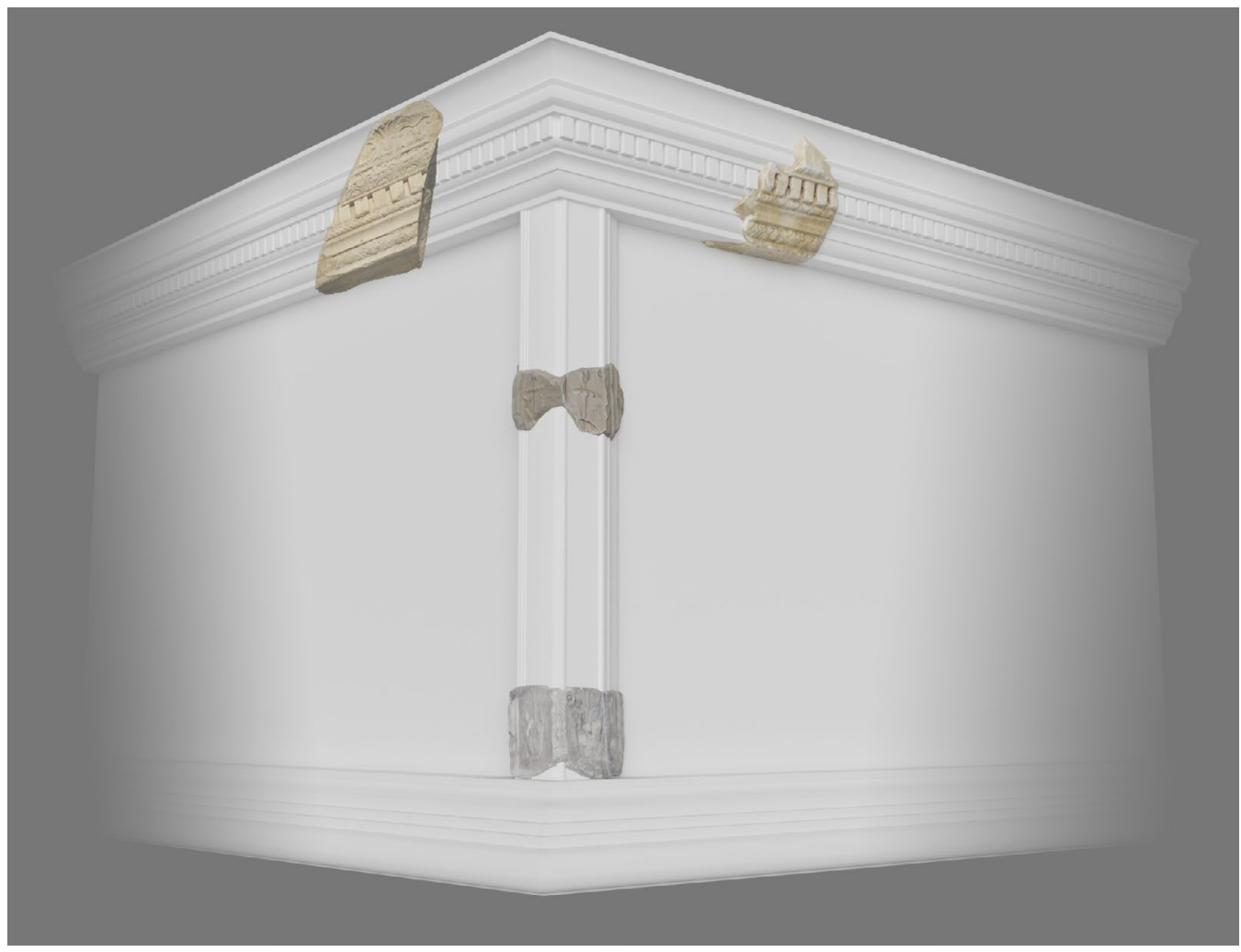

Figura 12: Hipótesis de reconstrucción virtual del altar cordobés con las cuatro piezas estudiadas. Elaborado por Carmen Rodríguez Gómez con la colaboración científica de Massimo Gasparini y el autor 


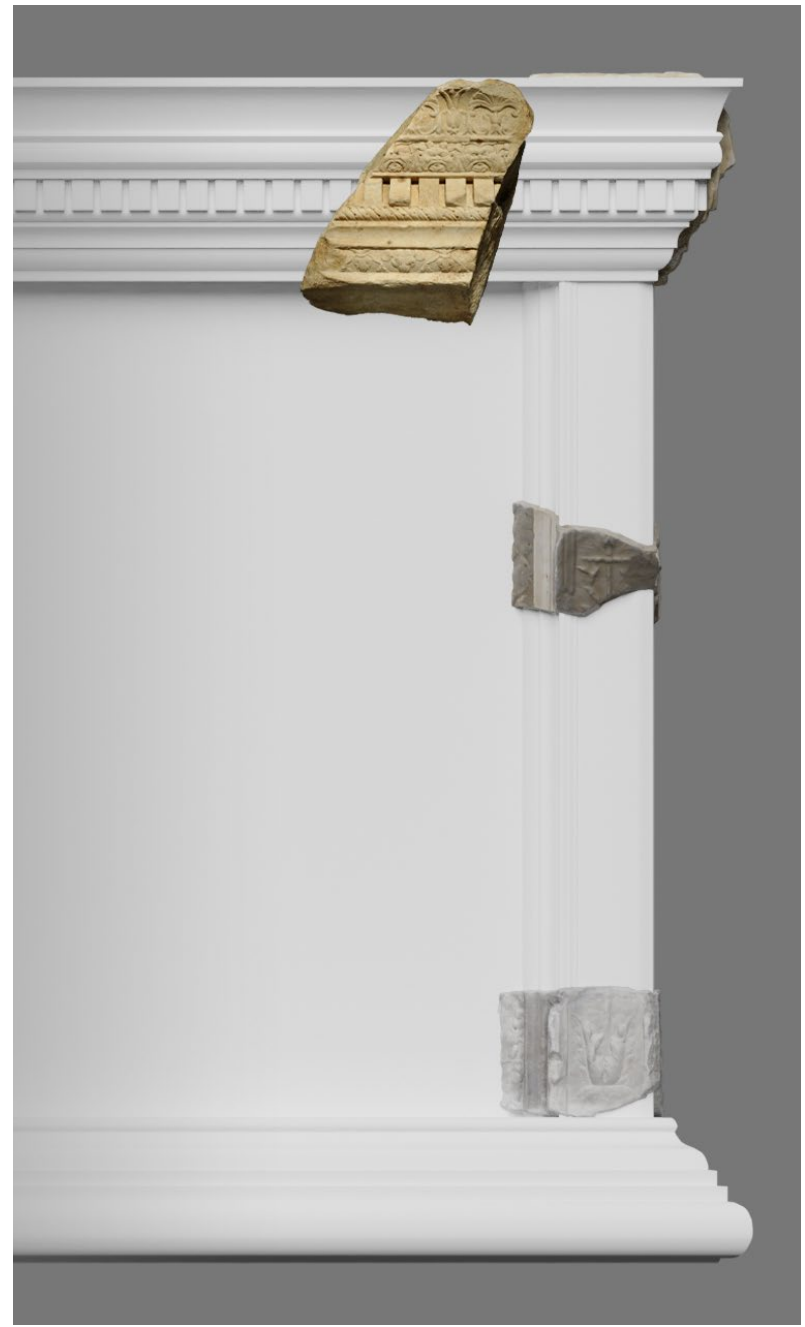

Figura 13: Detalle del altar con tres piezas ensambladas. Elaboración de Carmen Rodríguez Gómez con la colaboración científica de Massimo Gasparini y el autor por un lado, todavía no se ha detectado ejemplos de este tipo elaborados por piezas; además, con toda probabilidad esta nueva tipología, si se nos permite el término, estaría destinada no sólo a satisfacer las necesidades de familias privilegiadas de la Urbs, sino también, sobre todo, diría yo, para la exportación, por lo que habría que buscar fuera de Roma otros ejemplos que añadir al cordobés aquí estudiado. O. Dräger menciona algunos ejemplos de este tipo particularmente rico en decoración entre los que destaco un altar conservado en la Sala dei Busti de los Museos Vaticanos con diversas escenas dionisiacas (Dräger, 1994: 47, Kat. 100, Taf. 6 y 7) fechado en el tercer cuarto del siglo I a. C.

A fin de facilitar al lector la imagen hipotética del altar aquí estudiado, presentamos dos imágenes donde se han reproducido los fragmentos estudiados en este trabajo dentro de un modelo virtual de altar del tipo antes mencionado (Figs. 12 y 13).

Un paralelo razonable de altar parecido al que aquí proponemos puede verse en el foro de Cuicul (Fig. 14) con algunas diferencias bien apreciables pero que confirman las características conocidas de las piezas cordobesas: empleo de placas, esquinas formadas por piezas aparte (en el caso del altar africano, cuadrangulares; hexagonales en el caso cordobés); el ejemplo de Cuicul nos permite, además, avanzar en la imagen de la base y coronamiento de las pilastras de esquina que estarían algo proyectadas al exterior.

\section{PROCEDENCIA}

Conocemos la procedencia de dos de los fragmentos aquí analizados; la cornisa número 1.1 tiene como referencia del Museo Arqueológico el n. ${ }^{\circ}$ de Registro 28476 y las siguientes siglas: C.M. 21-11-74. Estas

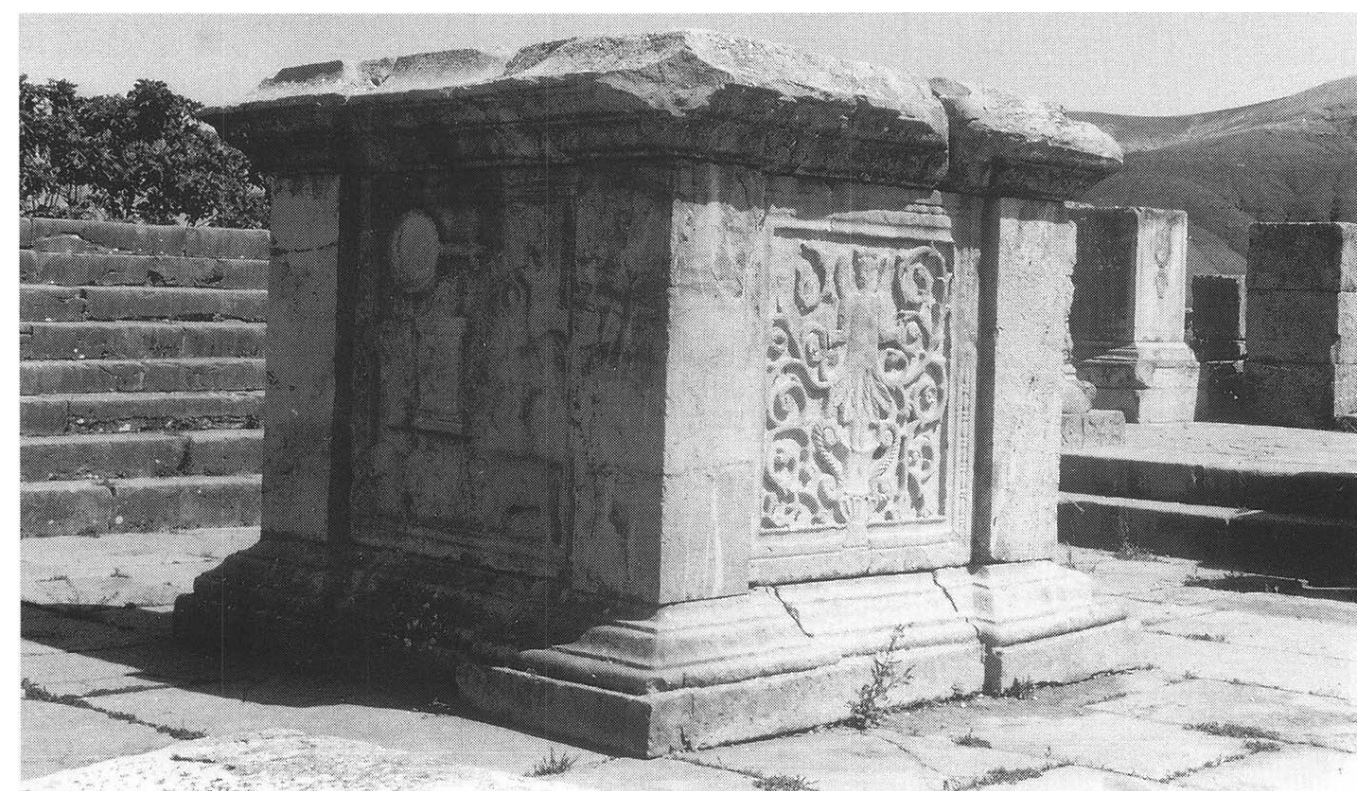

Figura 14: Altar del foro severiano de Cuicul (Djemila). Imagen recuperada de https://journals.openedition.org/encyclopedieberbere/ docannexe/image/2185/img-3.png 
siglas indican su pertenencia a la Colección Muñoz, comprada por el Museo el 28 de enero de 1975 y formada por distintas piezas de las que, por desgracia, no se tiene constancia acerca del lugar de procedencia dado que según los expedientes que obran en poder del Museo, fueron recuperadas de los vacies de Córdoba; de la segunda cornisa no tenemos más información que la que nos proporciona la página web antes mencionada donde se asegura su origen cordobés y que perteneció a la colección de Francisco A. Mohedano, quien adquirió la pieza en 1970, es decir, cuatro años antes de que la pieza número 1.1 ingresara en el Museo Arqueológico; la tercera pieza fue localizada en el número 16 de la calle Cruz Conde de Córdoba, es decir, en un solar muy cercano, durante el periodo romano, al foro colonial de la ciudad; como dijimos antes, las primeras noticias de su descubrimiento las proporciona Samuel de los Santos Gener en 1955 (Santos Gener, 1955: 845, fig. 30). Finalmente, la cuarta pieza formaba parte de la Colección del arquitecto Enrique Tienda, como ya tuvimos ocasión de comentar, que tenía su domicilio en la calle Morería de Córdoba, o sea, junto al foro colonial y en lo que en su momento sería el complejo de culto imperial dedicado a divus Augustus (también conocido en la bibliografía como Forum Novum o Forum Adiectum). Tras el fallecimiento del Sr. Tienda, esta colección pasó a manos de la Congregación de las Hermanas de la Cruz, quienes donaron esta pieza a un particular. El resto de lo que fue colección Tienda está hoy depositado en el Museo Diocesano de Córdoba.

Hay razones fundadas para pensar que el lugar de procedencia de la pieza de la que formaban parte los fragmentos aquí vistos fuese algún recinto monumental de la ciudad romana de Córdoba entre los que pueden mencionarse, por ser bien conocidos, el foro de la colonia, el centro de culto imperial dedicado a divus Augustus o el teatro; y ello por dos razones: en primer lugar, sabemos que una parte importante de la colección Tienda, a la que antes me refería y que fue el propietario de la segunda de las pilastras (pieza 1.4), procede de solares cercanos a la casa de este coleccionista en la calle Morería; la escultura colosal aparecida en la misma calle junto a dicha casa sería el mejor testimonio de lo que decimos porque apareció a las puertas de su casa (Peña, 2011: con bibliografía.). Por otro lado, la aparición en la calle Cruz Conde 16, muy próxima a la calle Morería, de la tercera de nuestras piezas no debe de extrañar en absoluto puesto que parece probada la existencia de un depósito de mármoles en esa zona destinado a ser quemados para obtener cal dentro del proceso generalizado de reaprovechamiento de material en el periodo tardoantiguo (Márquez, 1998: 208 s.) por lo que no es extraño que aparezcan fragmentos de piezas tanto de arquitectura como de escultura pertenecientes ya sea al foro colonial o al recinto de culto imperial. Un tercer espacio donde podría encajar sería el teatro que, aunque está algo más alejado de la zona donde apareció la pieza antes mencionada, es lugar de representación tradicional de Dionysos y su cortejo como tendremos ocasión de comentar más adelante.

Ante estas noticias parciales y poco concretas no podemos decantarnos con seguridad sobre cuál pueda ser la zona de origen de este hipotético altar; podría tener una función cultual en algún recinto sacro dedicado a Dionysos, todavía no conocido, en el centro monumental de la ciudad; poco sentido tendría su vinculación con otro tipo de culto oficial en el foro colonial o bien en el centro de culto imperial de la calle Morería que, recordemos, fue un extraordinario complejo construido en el periodo tiberiano para rendir culto a divus Augustus (Peña, Ventura y Portillo, 2011; Portillo, 2016; Márquez, 2017: 219-221; Garriguet, 2017) por el significado de los relieves arriba comentados. La presencia de Dionysos o de personajes de su cortejo se vincula de forma estrecha a ambientes domésticos o de su propio culto vinculados con el teatro. A pesar de ello, no podemos dejar de mencionar el ejemplo, a modo de paralelo, de un fragmento de candelabro con una decoración muy similar a base de máscaras procedente nada menos que del Foro Romano en la capital del imperio, y más concretamente cerca de la Basilica Aemilia, que hoy se encuentra conservado en el Antiquario Forense (Cain, 1985: cat. 71). También del Foro de Aquileia se conocen relieves con decoración de máscaras en sus balaustradas (Fuchs, 1986: 81, nota 118; 1987, 186). Pero, repito, a pesar de estos últimos paralelos que sacamos a colación por cuestiones metodológicas, no es un motivo muy presente en estos ámbitos forenses, por lo que nuestras miras para su ubicación deben dirigirse a otros ámbitos.

Esto supuesto, además de su hipotético origen forense, otra posible ubicación sería el teatro patriciense que, además, no se encuentra demasiado lejos de la zona de procedencia de las piezas y donde encajaría perfectamente este tipo de personajes y temas dionisiacos (Fuchs, 1986: 80 ss.). En ese sentido, los altares vinculados a este espacio escénico conocidos en otras ciudades representan, con sus diferencias morfológicas, un extraordinario paralelo para nuestro altar que, repito, aun siguiendo un esquema diverso en lo que a su forma se refiere, podría vincularse por la decoración de ambiente dionisíaco con el ambiente del teatro.

Sobre el programa ornamental del teatro de la Córdoba romana (Márquez, 2002) podemos indicar que cuenta con varias piezas vinculadas con el cortejo báquico además de otras esculturas de temática muy diversa entre los que destaca la presencia de un retrato de Antonino Pío y relieves de provincia.

Pero sin duda, el mejor ejemplo, junto al altar de Cuicul que podemos presentar es el de una ciudad de la Galia; me refiero a los bien conocidos altares apolíneos del teatro de Arles (Fig. 15), traído ahora a colación por la forma rectangular (como el nuestro), muy en especial el que representa en el centro de la composición a Apolo flanqueado por dos laureles porque son los más cercanos que, desde un punto de vista formal, conocemos (Coulot, 2019: 124 ss., Abb. 233 y 234) y 


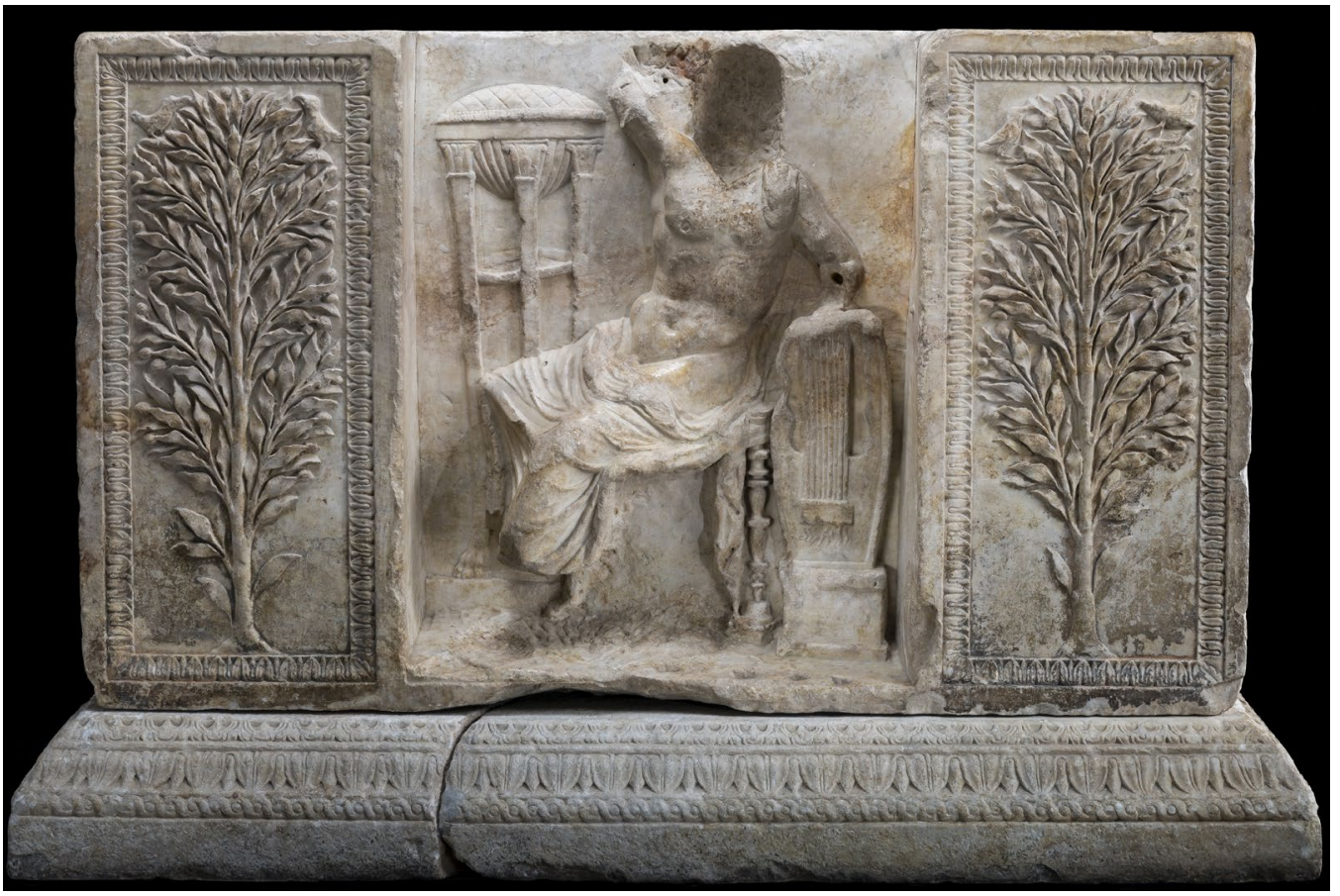

Figura 15: Altar de Apolo del teatro de Arles. Fotografía: Autel d'Apollon, FAN.1992.357, Musée départemental Arles antique C Lionel Roux

que, además, comparten espacio con otros elementos de clara vinculación dionisiaca (Coulot, 2019: Abb. 238-242).

\section{CONCLUSIONES.}

Todo lo expuesto hasta ahora demuestra la realización de un altar en diversas piezas, hoy diseminadas en varios lugares, que serían:

1. La base que no conocemos pero que con toda seguridad debía de tener (Figs. 12 y 13)

2. Pilastras angulares de sección hexagonal (piezas 1.3 y 1.4; Figs. 5-9)

3. Placas relivarias cuya temática nos es, lamentablemente, desconocida

4. Cornisa profusamente decorada (piezas 1.1 y 1.2; Figs. 1-4), también realizada en bloques

5. Cuerpo macizo formado por una pieza de cemento o de algún material lítico, sobre el que se colocaban a modo de revestimiento las anteriores piezas

Respecto a la decoración de los materiales aquí analizados hay que señalar en primer lugar que, si bien cuentan con una gran calidad técnica, servirían como marco ornamental de la placa relivaria que hoy día no conocemos; así las cosas, los relieves vegetales y animales de pilastras y cornisas actúan de modo similar al ya comentado de piezas neoáticas: aunque tienen una clara intención de vincularse con Dionysos/Liber, también puede pensarse que desarrollan una cita culta dentro de un paisaje idílico, marco predilecto para la colocación de un altar en un ambiente religioso como podría ser un santuario; no olvidemos, a través de los paralelos citados en apartados anteriores, cómo las distintas imágenes aquí empleadas y analizadas aparecen, del mismo modo, ocupando diversas zonas en similares elementos de prestigio representados por altares, cráteras y sobre todo por los candelabros neoáticos en zonas siempre privilegiadas del imperio.

La función como altar nos parece la más adecuada dadas las características de todas estas piezas, de sus dimensiones y su decoración; a pesar de que no podemos asegurar su pertenencia a nuestro altar, quisiera sacar a relucir un fragmento relivario que tiene como elemento ornamental la cabeza de un toro (Márquez, 2004: 342, fig. 6; Portillo, 2016: 543, lám. 11, cat. 7); la placa a la que pertenece este relieve tiene $5 \mathrm{~cm}$ de grosor, por lo que por dimensiones, podría empotrarse en algunas de las caras lisas de las pilastras del altar aquí estudiado; y por temática también, habida cuenta de la relación de dicho animal con los sacrificios tan presentes en todos los espacios de culto. Su ubicación en el teatro o en alguna de las plazas de representación patricienses es algo que no podemos en estos momentos confirmar.

La realización por partes de un elemento que no debió tener un volumen excesivo se une a otras características presentes en los distintos elementos conservados que nos inducen a pensar en una importación; ya comentamos más arriba la hipótesis de P. Pensabene según la cual las pilastras de Cherchel fueron realizadas por talleres romanos u ostienses (Pensabene, 1982: 159; Mathea-Förtsch, 1999: 100); la semejanza de nuestros relieves con los estudiados por estos investigadores hace que creamos que las piezas cordobesas fueron producto 


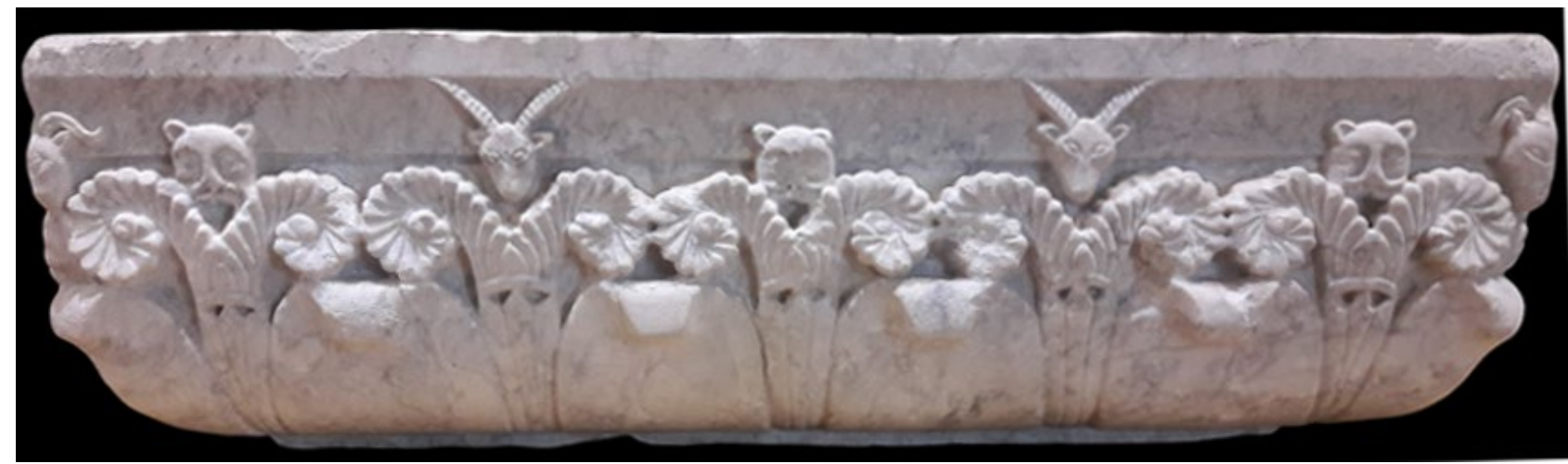

Figura 16: Fuente procedente de la Almunia de ar-Rumaniya conservada en el Museo Arqueológico de Córdoba. Fotografía: autor

de los mismos talleres; además, la calidad del relieve de las cornisas y su singularidad ornamental abogan por una realización foránea, probablemente de Roma o sus alrededores. Obviamente podría pensarse en un taller itinerante como alternativa, taller que debió demostrar una auténtica pericia para elaborar in situ esta pieza; pero si se hubiese dado esta situación, lo más probable hubiese sido que se labrase la pieza en un solo bloque; además, para apoyar esta idea hemos de recordar que ya se conocen en la Córdoba augustea otras piezas importadas con toda probabilidad, que coinciden además con nuestras piezas en la calidad artística además de una misma cronología: es el caso del puteal que representa la disputa del Âtica (León, 2018: 133-137) o bien un magnífico relieve de guirnalda (Márquez, 1998: cat. 903,141 y 197) así como una base de altar de riquísima decoración (Márquez, 1997: 70 s., lám. 1, fig. 1). Quiero con todo ello decir que la importación de materiales de altísima calidad artística como son los cuatro fragmentos aquí analizados encajaría perfectamente en este ambiente de intercambio entre la capital y ciudades privilegiadas provinciales; tal idea es la que subyace en la publicación reciente de una escultura que representa a un emperador sedente de la que pensamos también fue importado desde Italia, y que coincide con nuestros fragmentos en la elevada calidad artística y en el hecho de haberse transportado en diversas partes que luego se habrían ensamblado en el lugar de destino, o sea, el Centro de Culto imperial de la calle Morería, según nuestra hipótesis (Márquez y Gasparini, 2020). En apoyo a esta idea, sabemos por los trabajos de $\mathrm{H}$. $\mathrm{U}$. Cain que algunos talleres urbanos comienzan a elaborar candelabros de mármol en piezas para facilitar su comercio (Cain, 1985: 12) y también que las pilastras decoradas con estos motivos serían, del mismo modo, objeto de comercio; nada impediría, en consecuencia, que un elemento ornamental tan preciado pudiera haber llegado a nuestra ciudad procedente del mercado de arte en el periodo augusteo o tiberiano para decorar algunos de sus edificios más representativos.

No puedo concluir sin hacer una referencia al periodo islámico de esta ciudad (Anderson, Arnold y Vallejo, 2015: 133 s., fig. 64); la similitud de motivos animales, su alternancia, las referencias clásicas aportadas por las hojas de acanto, todo ello hace que finalicemos este trabajo con una imagen de una fuente localizada en la Almunia de ar-Rumaniya (Fig. 16) que demuestra, una vez más, la continuidad de motivos en el ámbito mediterráneo durante el periodo clásico y el medieval islámico.

\section{REFERENCIAS}

Agnoli, N. (2013). Rilievi Grimani. En E. La Rocca, C. Parisi, A. Lo Monaco, C. Giroire y D. Roger (Eds.). Mostra Augusto (pp.248-249). Milano: Electa.

Anderson, G., Arnold, F. y Vallejo, A. (2015). C. Decoration. En F. Arnold, A. Canto y A. Vallejo (Eds.). Munyat ar-Rumaniya. Ein islamischer Landsitz bei Córdoba (pp. 127-147). Madrider Beitrage, 34, 1. Wiesbaden: Ludwig Reichert Verlag.

Boschung, D. (1993). Grabaltare mit Girlanden und frühe Girlandensarkophage. Zur Genese der Kaiserzeitlichen Sepulkralkunst. En G. Koch (Ed.). Grabeskunst der römischen Kaiserzeit (pp. 37-42). Mainz am Rhein: Philipp von Zabern.

Cain, H. U. (1985). Römische Marmorkandelaber. Mainz am Rhein: Philipp von Zabern.

Cain, H. U. (1988). Chronologie, Ikonographie und Bedeutung der römischen Maskenreliefs. Bonner Jahrbuch, 188, 107-222.

Chaisemartin, N. de. (2006). La frise ionique à masques scéniques du Propylon du Sébasteion d'Aphrodisias. Revue Archéologique, 41(1), 33-82. DOI: https://doi.org/10.3917/ arch.061.0033

Coulot, Ch. (2019). Citharam iam poscit Apollo victor. Architektur und Bauornamentik der Scaenae frons des augusteischen Theater von Arles. Tübinger Archaeologische Froschungen, 30. Rahden: Verlag Marie Leidorf GmbH.

Dräger, O. (1994). Religionem significare. Studien zu reich verzierten römischen Altären und Basen aus Marmor. Mainz am Rhein: Philipp von Zabern.

Fallmann, D. (2015). Reliefbecher mit Pansfratzen umgeben von Weinranken. En J. A. Dickmann y A. Heinemann (Eds.). 
Von trinken und Bechern. Das antike Gelage im Umbruch (pp. 293-294). Freiburg: Archäologische Sammlung der Universität.

Fuchs, M. (1986). Il teatro romano di Fiesole. Corpus delle sculture. Roma: L'Erma di Bretschneider.

Fuchs, M. (1987). Untersuchungen zur Ausstattung römischer Theater in Italien und den Westprovinzen des Imperium Romanum. Main am Rhein: Philipp von Zabern.

Garriguet Mata, J. A. (2017): Tácito, el templo romano de la c. Morería (Córdoba) y el origen del culto provincial en Baetica. Zephyrus, LXXX, 113-130. DOI: https://doi. org/10.14201/zephyrus201780113130

Golda, T. M. (1997). Puteale und verwandte Monumente. Eine Studie zum römischen Ausstattungluxus. Mainz am Rhein: Verlag Philipp von Zabern.

Grassinger, D. (2008). Doppelherme. En D. Grassinger, T. de Oliveira y A. Scholl (Eds.). Die Rückkehr der Götter. Berlin verborgener Olymp. Berlin: Schnell Steiner.

Heinemann, A. (2011). Ein dekorativer Gott? Bilder für Dionysos zwischen griechischer Votivpraxis und römischem Decorum. En Renate Schlessier (Ed.). A different God? Dionysos and ancient Polytheism (pp. 391-413). Berlin: De Gruyter. DOI: https://doi.org/10.1515/9783110222357.391

Hesberg, H. von. (1996). La decorazione architettonica di Cordoba. Sulla funzione dell'ornamentazione architettonica in una città romana. En P. León (Ed.). Colonia Patricia Corduba. Una reflexión arqueológica (pp. 155-174). Sevilla: Consejería de Cultura.

Lapuente, P. y Álvarez, A. (2012). Métodos para la identificación de los mármoles. En V. García Entero (Ed.). El marmor en Hispania. Explotación, uso y difusión en época romana (pp. 73-90). Madrid: Librería UNED.

La Rocca, E. (2021). Hermes-Thoth e Dionyso redentore. Dall'Egitto dei Tolomei al tardoantico: studi sul mosaico della Casa di Aion a Nea-Paphos. Bullettino della Commissione archeologica comunale di Roma, Supplementi, 28. Roma-Bristol: Erma di Bretschneider.

Leon, Ch. (1971). Die Bauornamentik des Trajansforums. Wien: Böhlau.

León, P. (2018). Tres estampas arqueológicas en los albores de Colonia Patricia. Boletín de la Real Academia de Córdoba, 167, 129-142.

León, P. (2020). El influjo alejandrino y tolemaico en la Hispania romana. En G. Gentili y M. Almagro-Gorbea (Coms.). Cleopatra y la fascinación de Egipto (pp. 89-94). Milano: Skira.

Lo Monaco, A. (2010). La maschera nel mondo antico tra scena e arredi domestici. En E. La Rocca (Ed.). Il sorriso di Dionyso (pp. 103-126). Torino: Umberto Allemandi.

Márquez, C. (1997). Artes decorativas en la Córdoba romana Anales de Arqueología Cordobesa, 8, 69-94. DOI: https://doi. org/10.21071/aac.v0i.11322
Márquez, C. (1998). La decoración arquitectónica de colonia Patricia. Una aproximación a la arquitectura y urbanismo de la Córdoba romana. Córdoba: Cajasur.

Márquez, C. (2002). La ornamentación escultórica: programas. En A. Ventura, C. Márquez, A. Monterroso y M. A. Carmona (Eds.). El teatro romano de Córdoba (pp. 121-123). Córdoba: Universidad de Córdoba.

Márquez, C. (2004). La decoración arquitectónica en Colonia Patricia en el periodo julio-claudio. En S. Ramallo (Ed.). La decoración arquitectónica en las ciudades romanas de Occidente (pp. 337-354). Murcia: Universidad de Murcia.

Márquez, C. (2017). El desarrollo urbano y monumental. En J. F. Rodríguez Neila (Ed.). La ciudad y sus legados históricos. Córdoba romana (pp. 207-248). Córdoba: Real Academia de Córdoba.

Márquez, C. y Gasparini, M. (2020). Escultura de emperador sedente en colonia Patricia. Archivo Español de Arqueología, 93, 273-182. DOI: https://doi.org/10.3989/aespa.093.020.008

Mathea-Förtsch, M. (1999). Römische Rankenpfeiler und -Pilaster. Mainz am Rhein: Philipp von Zabern.

Meilán Jácome, P. (2013). Bacchus and Felines in Roman Iconography: Issues of Gender and Species. En A. Bernabé, M. Herrero de Jáuregui, A. I. Jiménez San Cristóbal y R. Martín Hernández (Eds.). Redefining Dionysos (pp. 526539). Mythos Eikon Poiesis, 5. Göttingen: De Gruyter. DOI: https://doi.org/10.1515/9783110301328

Pensabene, P. (1982). La decorazione architettonica di Cherchel: cornici, architravi, soffiti, basi e pilastri. En 150 Jahr-Feier des deutsches Archäologisches Institut Röm (pp. 116-169). Römisch Abteilung, suppl., 25. Mainz: Deutsches Archäologisches Institut.

Peña, A. (2011). Estatua militar, posible representación de Eneas. En M. D. Baena, C. Márquez y D. Vaquerizo (Eds.). Córdoba reflejo de Roma (pp. 308 y 401). Córdoba: Diputación Provincial de Córdoba.

Peña, A., Ventura, A. y Portillo, A. (2011). El templo consagrado a divo Augusto y su temenos (Forum Novum). En M. D. Baena, C. Márquez y D. Vaquerizo (Eds.). Córdoba reflejo de Roma (pp. 59-67). Córdoba: Diputación Provincial de Córdoba.

Portillo, A. (2016). El templo de la calle Morería en el Forum Novum de Colonia Patricia. Análisis arquitectónico y funcional. (Tesis doctoral). Universidad de Córdoba. Córdoba. Recuperado de: https://helvia.uco.es/xmlui/ handle/10396/13226

Rumscheid, F. (1994). Untersuchungen zur kleinasiatischen Bauornamentik des Hellenismus. Mainz am Rhein: Verlag Philipp von Zabern.

Salvetti, C. (2020). Pinturas y mosaicos de tema nilótico. En G. Gentili y M. Almagro-Gorbea (Coms.). Cleopatra y la fascinación de Egipto (pp. 75-79). Milano: Skira.

Santos Gener, S. de los. (1955). Memoria de las Excavaciones del Plan Nacional realizadas en Córdoba (1948-1950). Comisaría General de Excavaciones Arqueológicas, Informes 
y memorias, 31. Madrid: Ministerio de Educación Nacional, Dirección General de Bellas Artes.

Sauron, G. (1982). Discours symbolique et formes décoratives à Rome à l'époque augustéenne: problèmes de méthode. Mélanges de l'Ecole Française de Rome, 94(2), 699-713. DOI: https://doi.org/10.3406/mefr.1982.1341

Sauron, G. (1994). Quis Deum? L'expression plastique des idéologies politiques et religieuses à Rome à la fin de la République et au debut du Principat. Bibliothèque des Écoles Françaises d'Athènes et de Rome, 285. Roma: École Française de Rome. DOI: https://doi.org/10.3406/ befar.1994.1254

Sinn, F. (1987). Stadtrömische Marmorurnen. Mainz am Rhein: Verlag Philipp von Zabern.
Toynbee, J. M. C. (1996). Animals in roman life and Art. Baltimore: Johns Hopkins University Press.

Ungaro, L. (2004). La decorazione architettonica del foro di Augusto a Roma. En S. Ramallo Asensio (Ed.). La decoración arquitectónica en las ciudades romanas de Occidente (pp. 17-35). Murcia: Universidad de Murcia.

Viscogliosi, A. (1996). Il tempio di Apollo «in Circo» e la formazione del linguaggio architettonico augusteo. Supplemento Bullettino della commissione archeologica comunale di Roma, 3. Roma: L'Erma di Bretschneider.

Zanker, P. (1992). Augusto y el poder de las imágenes. Madrid: Alianza Editorial. 
